\title{
Anterior Approaches to Thoracic and Thoraco-Lumbar Spine
}

\author{
Aydin Nadir \\ Department of Thoracic Surgery, Cumhuriyet University, \\ School of Medicine Sivas- \\ Türkiye
}

\section{Introduction}

Anterior surgical approaches have been used for lower cervical, thoracic, and upper lumbar vertebrae since the beginning of the second half of the 20th century. Hodgson et al. were the first surgeons to perform spinal fusion with anterior approach for the treatment of a paraplegic patient with Pott's disease in 1956. Cauchoix and Binet reported access to vertebral corpuses from C7 to T4 using a median sternotomy in 1957. Moreover, in 1969, Perot and Munro described trans-thoracic removal of a thoracic disc causing compression on the spinal cord. Similarly Dwyer et al. described the use of anterior approach for the surgical treatment of scoliosis (1969) and Harrington anteriorly stabilized vertebral fractures due to tumors with methyl methacrylate. First investigators to describe anterior approach with VATS were Mack et al. (1993) (1-4).

Surgical interventions for vertebral fractures include anterior, posterior and combined approaches, with the anterior approach providing a very good exposure. Posterior approach poses some technical inadequacy, with recurrence rates higher than the anterior approach. In fractures causing angle deformity, anterior approach has been proposed as the appropriate method. In fragmented fractures of the thoracolumbar spine, corpectomy with anterior approach and grafting is an effective treatment modality (2,5-8). Anterior approach not only provides a very good exposure to allow for decompression of the spinal canal, but also it may help to improve the neurological status in patients with neurological deficits. However, morbidity, which is mostly respiratory (atelectasis, respiratory failure, etc.), is more frequent with anterior approach (2).

Anterior approach was first reported by Dwyer and Zielke for scoliosis surgery, with a correction angle between $28,3^{\circ}-66,6^{\circ}$. The average percentage of patients in whom correction can be achieved is $57.5 \%$. Bilateral approach can be used or posterior approach can be combined with unilateral approach $(1,3,9,10)$. In patients undergoing posterior surgery alone, the likelihood of requiring a second operation is high (11). In cases with scoliosis, the procedure should be performed at the side with widened intercostal spaces and convex deformity. When the thoracotomy is performed at the point of maximum deformity, better exposure is provided. 


\subsection{Indications}

The primary indications for anterior approach in vertebral surgery include the conditions associated with the destruction of one or more vertebral corpuses and intervertebral discs, vertebral fractures, and deformities (Table 1). Whilst patients with deformities constitute the main patient population in childhood and adolescence, degenerative diseases, malignancies, and infections are the prevailing indications among adults. Recently, traumatic fractures with or without neurologic deficits also represent another very important indication for the anterior approach in spinal surgery. Pain relief, stabilization of the deformity, cosmetic improvement, drainage of spinal infections, and reduction/prevention of neurological deficits are primary objectives of such procedures $(1,2,12,13)$.

\begin{tabular}{|l|}
\hline Infection \\
\hline Tuberculosis \\
\hline Pyogenic infections \\
\hline Parasitic infestation \\
\hline Malignancy \\
\hline Metastatic disease \\
\hline Involvement by adjacent tumors \\
\hline Primary tumor of vertebral body \\
\hline Degeneratif disc disease (herniation) \\
\hline Trauma \\
\hline Fracture-dislocation \\
\hline Compresion fracture \\
\hline Spinal deformities \\
\hline Scoliosis \\
\hline Kyphosis \\
\hline Lordosis \\
\hline
\end{tabular}

Table 1. Indications for anterior approach in spine surgery.

A multidisciplinary team effort involving thoracic surgeons, neurosurgeons, and orthopedic surgeons increases the likelihood of successful outcome with regard to operative results and improves the quality of life postoperatively. Inclusion of a thoracic surgeon in the team facilitates preoperative physiological assessments, determination of the best access route, and postoperative wound care $(1,2)$.

\subsection{Preoperative assessments}

The preoperative assessment algorithm is the same as that is used for thoracic surgery. Pulmonary function tests and blood gas analyses are useful both for preoperative and postoperative care and evaluation of the cardiac status may help prevent postoperative complications $(1,3,14,15)$.

Endotracheal general anesthesia with a single-lumen endotracheal tube is adequate for cervical (C7-T2) interventions, while endotracheal tubes with double-lumen should be preferred for thoracic and thoracolumbar procedures. Standard endotracheal tubes with a 
single-lumen may also be used. In our unit, tubes with a single-lumen are preferred. Retraction of the lung on the same surgical side without collapsing throughout the procedure will provide adequate exposure. This approach allows efficient use of time, and avoids some untoward occurrences such as malpositioning due to a double-lumen tube, inadequate aspiration, and intolerance to single-lung ventilation.

Appropriate positioning of the patient simplifies the surgery, shortens duration of surgery, and reduces the likelihood of morbidity. In cervical procedures the patient is brought to supine position, arms are adducted, and the head is slightly rotated toward the opposite side of the surgery. In case of open surgery between T2-12 or VATS, a standard lateral decubitus position is preferred. In our unit, we also prefer to use lateral decubitus position for anterior surgery in lower thoracic and upper lumber vertebrae during thoracoabdominal procedures. In this case, a backward angulation between $10^{\circ}-15^{\circ}$ toward the operation table provides better exposure.

Depending on the position of the lesion, four different anatomical levels may be defined as follows: C7-T2, T2-T6, T6-T12, T12-L3 or L4. For lesions between C7 and T2, the best approach consists of manubrium resection or partial sternotomy in addition to cervical resection, while right thoracotomy is appropriate for T2-T6 lesions. We prefer left thoracotomy starting from T3 level for traumatic vertebral fractures. Due to the close adjacency of the descending aorta, aortic mobilization may be required in anterior approaches at T3 and T4. In the upper thoracic levels between T2 and T6, thoracotomy should be performed at the same level with the lesion. Between T6-T12, procedures are performed via a left thoracotomy. At this level, thoracotomy at one or two level above the lesion may provide better exposure due to downward inclination of the ribs. For lesions between T12-L3, 4 a left thoracoabdominal approach should be undertaken. Removal of the $11^{\text {th }}$ or $12^{\text {th }}$ rib provides wider exposure. Particularly, removal of the $11^{\text {th }}$ or $12^{\text {th }}$ rib provides easy extrapleural access to L1-L4 $(2,14,15)$.

Over a 7-year period (2004-2011), 67 patients (17 females, 50 males) were operated on using an anterior approach at our institution (2). The most indication for surgery was trauma fracture in $50(75 \%)$ patients. Distribution of ethiologies of the patients according to access level was detailed in Table 2. Mean operation time was about 2 to 3,5 hrs, and estimated blood loss was approximately $1000 \mathrm{~mL}$. Among the 67 patients operated via the anterior approach, we observed four postoperative complications. One patient had empyema postoperatively which was treated with tube thoracotostomy and irrigation. Another patient with vertebral tumor developed hemorrhagic drainage $(1100 \mathrm{cc} / 24 \mathrm{~h})$ during the early postoperative period which resolved with conservative treatment. In two patients, wound infection developed which were treated with debridement and suturation.

Remainder of this chapter, the procedures will be described detailed with operative pictures and drawings especially the "thoraco-lumbar" procedure.

\subsection{Anterior approach to the cervicothoracic spine}

Anterior approach at cervicothoracic vertebrae poses some difficulties associated with the local anatomy and requires a good deal of anatomical knowledge of the bony, ligamentous, muscular, and neurovascular structures of the upper thoracic access routes. Cervical resection, partial resection of the manubrium and clavicle and advances in the surgical instrumentation provide adequate exposure. 


\begin{tabular}{|l|c|c|c|c|}
\hline \multirow{2}{*}{ Etiology } & \multicolumn{4}{|c|}{ Access level } \\
\cline { 2 - 5 } & $\begin{array}{c}\mathrm{T} 3-6 \\
\mathrm{n}\end{array}$ & $\begin{array}{c}\mathrm{T} 7-10 \\
\mathrm{n}\end{array}$ & $\begin{array}{c}\mathrm{T} 11-\mathrm{L} 3 \\
\mathrm{n}\end{array}$ & $\begin{array}{c}\text { Total } \\
\mathbf{n}\end{array}$ \\
\hline Trauma & 3 & 6 & $\mathbf{4 1}$ & $\mathbf{5 0}$ \\
\hline Tumor & 1 & $\mathbf{4}$ & 1 & $\mathbf{6}$ \\
\hline Tuberculosis & & $\mathbf{3}$ & 1 & $\mathbf{4}$ \\
\hline Scoliosis & 2 & & & $\mathbf{2}$ \\
\hline Hydatid cyst & 3 & & & $\mathbf{3}$ \\
\hline Kyphosis & 1 & & & $\mathbf{1}$ \\
\hline Kyphoscoliosis & & 1 & & $\mathbf{1}$ \\
\hline Total & $\mathbf{1 0}$ & $\mathbf{1 4}$ & $\mathbf{4 3}$ & $\mathbf{6 7}$ \\
\hline
\end{tabular}

Table 2. Distribution of ethiologies of the patients according to access levels.

A neck incision parallel to the sternocleidomastoid and extending up to the suprasternal notch is made in addition to partial sternotomy reaching T4 level (Figure 1a-b).

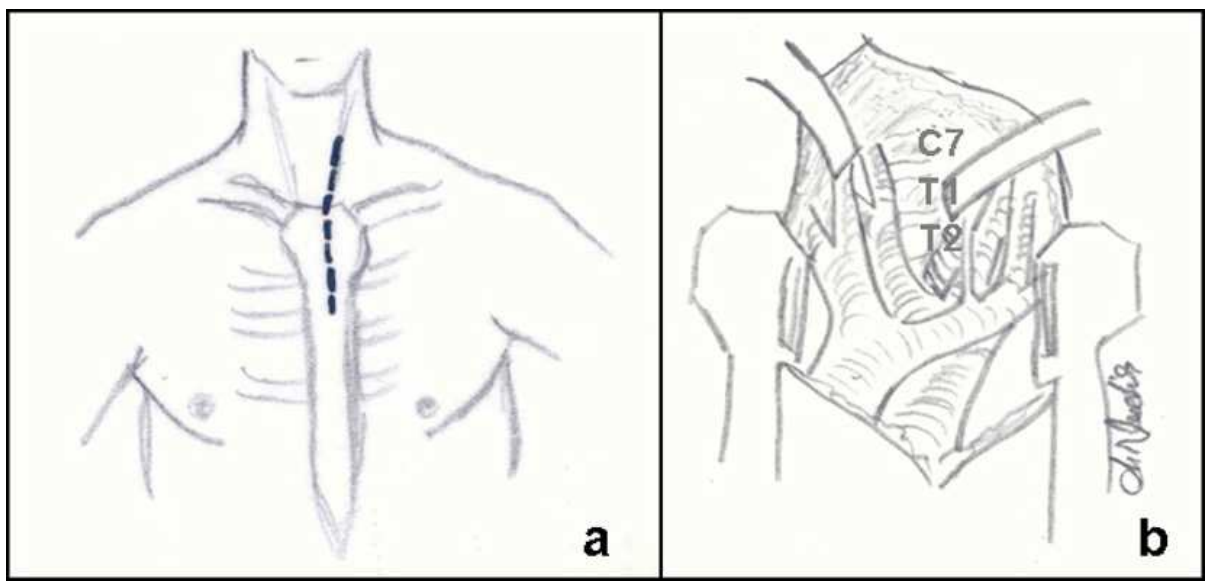

Fig. 1. Oblique neck and upper sternotomi incision is showing in figure 1a, and surgical exposure of $\mathrm{C} 2$ to $\mathrm{T} 2$ after the retraction of the vascular structures (Figure $1 \mathrm{~b}$ ). If clavicle is disarticulated form the manubrium, exposure can now be carried out to the T3.

A subplatysmal flap is prepared and strep muscles are pulled upwards to expose the sternoclavicular joint. Sternomastoid muscle is pulled laterally together with the jugular vein, and strap muscles are pulled toward medial side. Thus, the carotid sheath is positioned laterally, while the trachea and esophagus are positioned medially. Recurrent laryngeal nerve injury is avoided at the tracheoesophageal canal. Trachea and esophagus are pulled medially and the prevertebral fascia is exposed. Walsh et al recommend left sided neck incision due to decreased likelihood of injury to the contralateral laryngeal nerve, provided that there are no contraindications. Moreover, this approach provides better exposure from C4 to T3 $(1,14,15)$.

Sternotomy may not be necessary to access T1 vertebra. In that case, partial excision of the manubrium and/or clavicle may provide adequate exposure. The sternocleidomastoid 
muscle is cut with cautery, strap muscles are divided and pulled upward, the sternal part of the pectoralis major is stripped toward lateral side, clavicle is stripped subperiosteally, and disarticulated from sternum. In this way, vascular structures are pulled more laterally. If required, inferior thyroid vein is ligated and manubrium is partially removed. A Hemovac drainage tube is placed into the operation area and the layers are closed in accordance with normal anatomic alignment.

\subsection{Anterior Approach to the Thoracic Spine}

The access route is determined by the spinal level and length of the procedure. In deformities such as scoliosis, a thoracotomy is performed at the side with the wider intercostal space where the deformity reaches its apex, which is defined as the most prominent site of deformity. When required, the rib at the level of the incision can be removed. Removal of the third rib provides a good exposure in T1-T4 lesions $(1,2,6)$. Presence of the liver on the right side may result in technical problems; for this reason, we prefer left thoracotomy both for thoracic and lumbar procedures unless a contraindication exists. In situations such as the presence of a tumor or hydatid cyst, a left or right thoracotomy may be preferred depending on the location of the lesion $(13,16-18)$.

After intubation in supine position, a lateral decubitus position with the left side on top is used. A skin incision from the appropriate intercostal space and extending up to paraspinal muscles is made and thoracotomy is commenced. Care should be experienced to provide congruity between the incision and the costal margin. The anterior edge of the latissimus dorsi is determined and cut by cauterization in the posterior direction. Serratus anterior is cut toward anterior direction starting from its posterior side along the ribs. The first rib is palpated under the scapula, ribs are counted, and intercostals muscles are cut at the preferred level and thoracic cavity is accessed. We do not perform rib resection in middle and lower thoracic procedures, since adequate exposure is achieved. If pleural adhesions are present, they are released by blunt or sharp dissection. In case of intubation with a singlelumen tube, a compression is placed upon the lung to provide mild compression. The parietal pleura is opened in cephalad and caudad directions. The perforating arteries from the aorta, if required, intercostal artery and vein are ligated and the vertebrae are accessed (Figure 2). Following the procedure, bleeding control is achieved and a $32 \mathrm{~F}$ or $36 \mathrm{~F}$ chest tube is placed in the pleural cavity before the layers are closed according to normal anatomical alignment. After a daily drainage volume of 50 to $100 \mathrm{ml}$ and expansion of the lungs, the chest tube is usually withdrawn within $48-72$ hours.

\subsection{Anterior Approach to the Thoracolumbar Spine}

Anatomy of the diaphragm is important for thoracolumbar approaches. The apex of the dome of diaphragm may reach T7 level. It is attached to the xiphoid bone anteriorly; to the ribs and costal cartilages laterally (ribs 6 to 12); and to the corpuses and transverse processes of L1, L2, and L3 vertebrae with the lumbosacral arch via the crura posteriorly. The right and left diaphragmatic crura reach the upper lumbar vertebrae by forming the aortic hiatus. Since the diaphragm is innervated centrally, the incisions on the diaphragm should be peripheral and circular.

The Adamkiewicz artery is the principal arterial supply to the spinal cord in the lumbar area and its injury leads to paraplegia. It arises from the intercostal artery from the left and right 


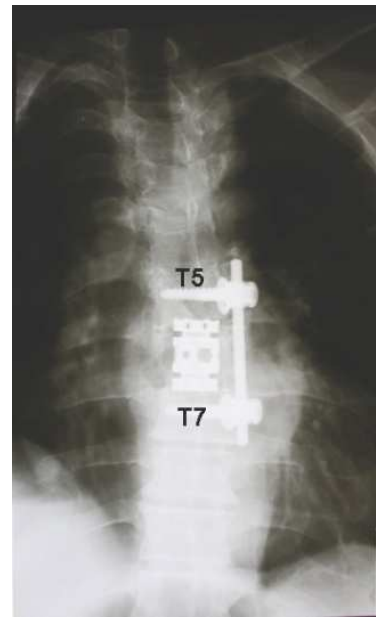

Fig. 2. The postero-anterior roentgenogram is showing fixating plates from $\mathrm{T} 5$ to $\mathrm{T} 7$ that is placed via left thoracotomy (Department of Neurosurgery, Cumhuriyet University, with permission).

side in $75 \%$ and $25 \%$ of the individuals, respectively $(1,14,15)$. Maximum effort should be carried out to avoid injuring this artery in the critical vascular zone of the spinal cord, i.e. between T7-L4, and particularly between T8-T10. If required, a preoperative selective angiography may be helpful in deciding on the surgical approach and preventing paraplegia. Somato-sensory potentials monitoring is useful to minimize the risk of cordal ischemia, particularly when performing an anterior approach through the left side.

An incision along the $10^{\text {th }}$ costal margin should be made for procedures between $\mathrm{T} 10$ and L1. In this regard, Hodgson recommends resection of the $9^{\text {th }}$ rib, while Dwyer recommends the $10^{\text {th }}$. We prefer a transthoracic approach from the $9^{\text {th }}$ intercostal space for T11-T12 lesions, while we access the thoracic cavity through the $10^{\text {th }}$ intercostal space for T12-L1 lesions (2). For T12-L1, we access the retroperitoneal area with a transthoracic approach (Figure 3a-b). For the majority of cases this negates the need for costal resections. The diaphragm is stripped anteriorly-laterally over the vertebral corpus to reach L1 without disrupting the integrity of the diaphragm (Figure 3,4). If access to L2 is required in this approach, an additional circumferential resection 4 to $5 \mathrm{~cm}$ in length is made in the costal diaphragm. For L2 lesions, a resection at the 12th $\mathrm{rib}$ is performed to reach L1-L2 extrapleurally.

In lateral decubitus position, a posterior angulation of $10^{\circ}-15^{\circ}$ is provided for better exposure when the patient lies. In deformities such as scoliosis or kyphoscoliosis, the side of convexity is preferred for surgery. Otherwise, a left thoracotomy is performed based on simpler mobilization of the aorta and spleen as compared to inferior vena cava and liver. A skin incision along the appropriate costal margin is made and extended anteriorly toward the iliac crest. After the muscles are severed by cautery, ribs are accessed and removed up to the costal cartilage by deperiostization. Thoracic cavity is accessed. If access to L1 level suffices for the procedure, then diaphragm is stripped anteriorly-laterally without disrupting its integrity and the retroperitoneal area is accessed (Figure 3-5) without entering 

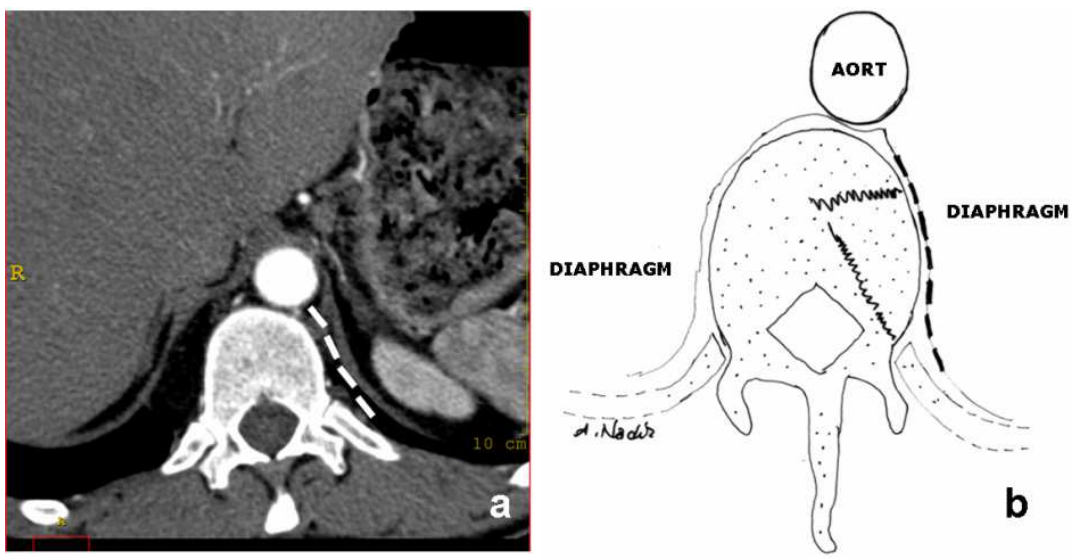

Fig. 3. The dotted lines showing the dissection plane either in radioloque (a), or schematic (b) illustration (The zig-zag lines in the $b$ frame represents vertebral fractures).

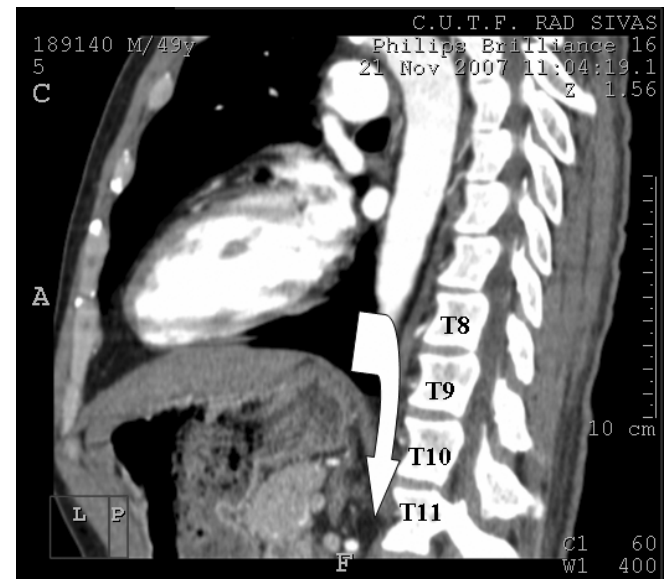

Fig. 4. White arrow indicating the pathway for reaching lumbal vertebrae during thoracotomy, in a sagittal section of a computed tomography. The diaphragm was separated from the antero-lateral vertebral corpus and the retroperitoneal space was reached without entering the abdomen, which allows access up to level L3.

the abdominal cavity. During the closure of diaphragm, infrequent sutures are usually adequate. Abdominal herniation is not expected, as only the retroperitoneal area has close association with the pleural cavity. In addition, the chest tube placed into the pleural cavity facilitates the postoperative drainage in the field of surgery.

For lesions at L2, a thoracoabdominal cut at the $11^{\text {th }}$ or $12^{\text {th }}$ costal region is performed (Figure 6-9). Removal of the $12^{\text {th }}$ rib results in simple access to L3 (Figure 10), and if required, to L4. If necessary, lateral fibers of the abdominal muscles (external oblique, internal oblique, and abdominal transverse) can be opened carefully $(14-16,19)$. Retroperitoneal area is reached without entering the pleural cavity. The porous tissues of the 


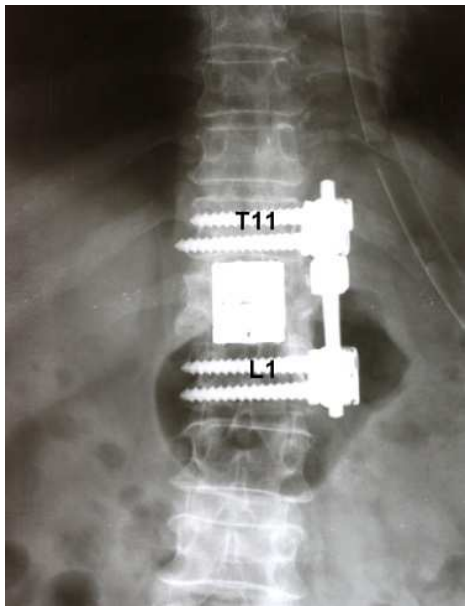

Fig. 5. The postero-anterior roentgenogram is showing the stabilization from T11 to L1. The diaphragm is divided from the vertebral corpus and reached the level L1 (Department of Neurosurgery, Cumhuriyet University, with permission).

retroperitoneum are retracted anteriorly and medially. The psoas muscle is stripped from its attachments to the L1 and L2 vertebrae using the vertebral column as a guide. Vertebrae are accessed. Sometimes thorax retractors may cause diaphragmatic injury, which can be closed by non-absorbable sutures for smaller defects. The lungs are fully expanded in coordination with the anesthesiologist. After absence of air in the pleural cavity is ascertained, the sutures placed on the diaphragm are ligated and the pleural cavity is closed without the need for a chest tube. Hemovac drains are placed in the field of surgery and under paraspinous muscles, and the layers are closed according to anatomy.

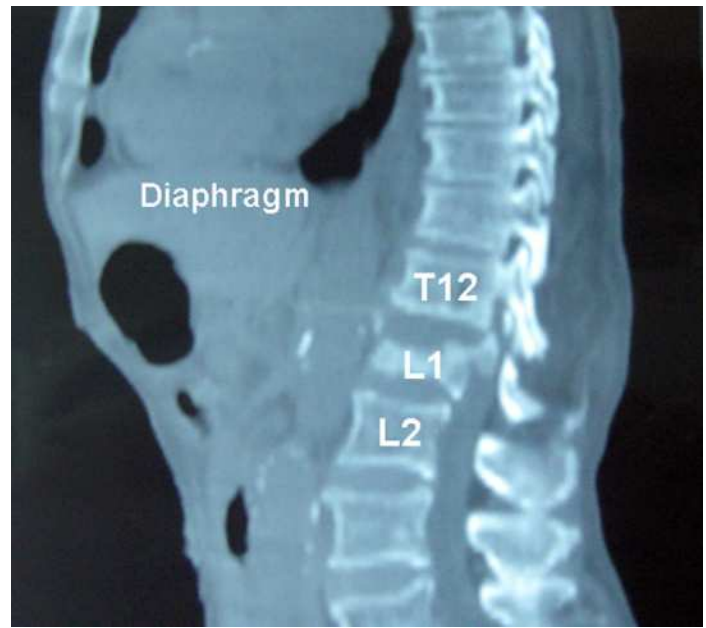

Fig. 6. The traumatic fracture in L1 vertebrae is revealed in the magnetic resonance imaging (Department of Neurosurgery, Cumhuriyet University, with permission). 


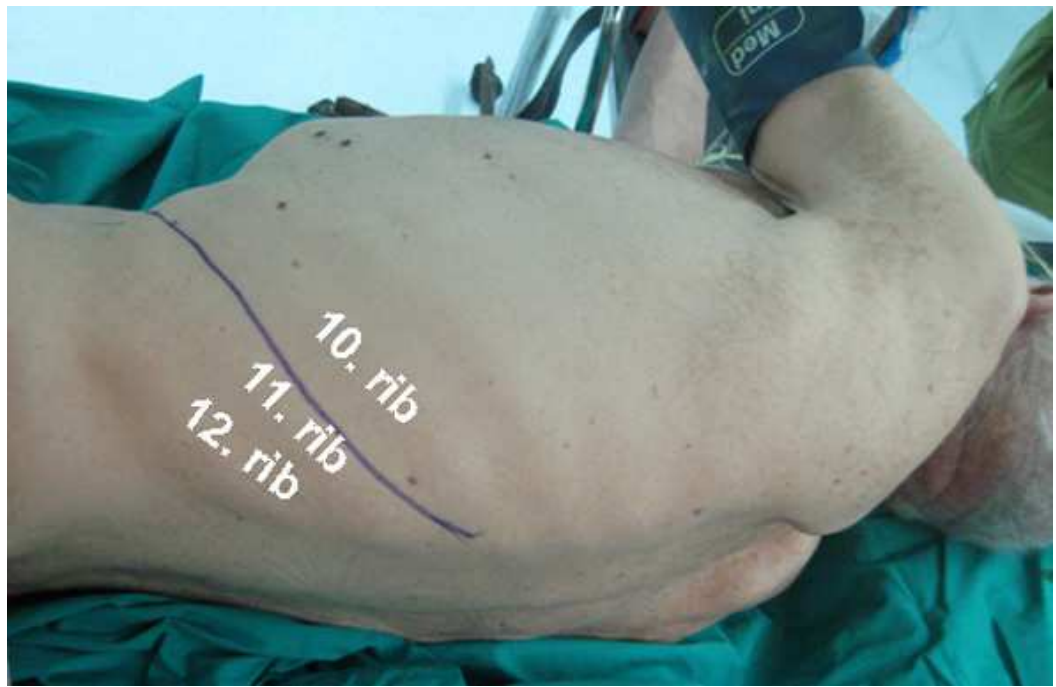

Fig. 7. The patient is placed in the lateral decubitus position with the left side up and is positioned in $10^{\circ}-15^{\circ}$ oblique chest position rotated to the posteriorly. The skin and subcutaneous tissue are opened from the lateral border of the paraspinous musculature to costal cartilage junction over the rib to be resected (Department of Neurosurgery, Cumhuriyet University, with permission).

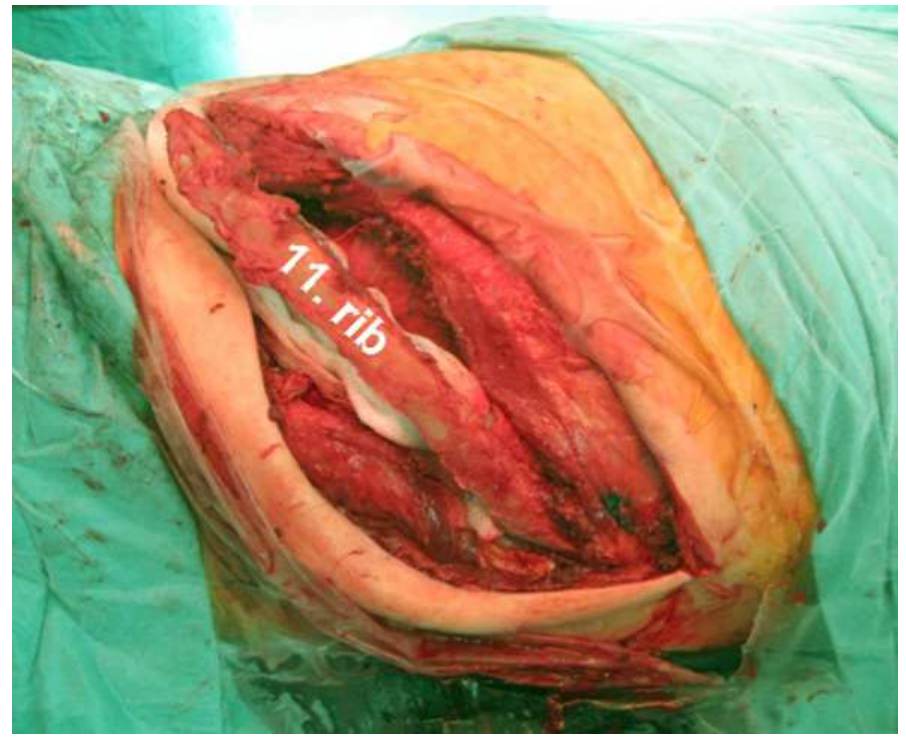

Fig. 8. The Periosteum is elevated first from the outer surface of the rib, then from the superior surface, followed by the inferior surface of the rib. The rib is cut as far anteriorly as between the costal cartilage junction and posteriorly at costotransverse joint (Department of Neurosurgery, Cumhuriyet University, with permission). 


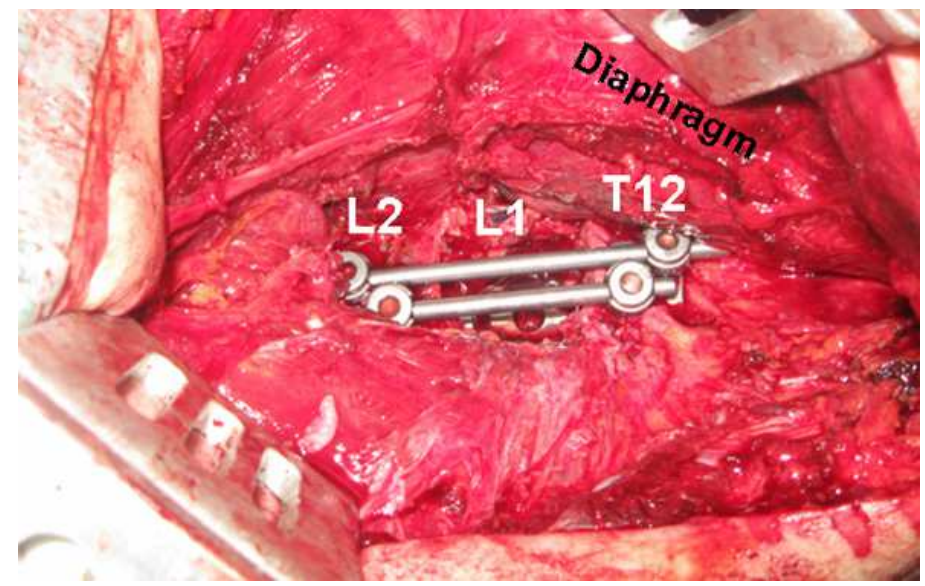

Fig. 9. Retroperitoneal area is accessed extrapleurally by the resection of $11^{\text {th }}$ or $12^{\text {th }}$ ribs depending on the location of the diaphragm. The intraoperative image of a patient following L1 corpectomy and stabilization by the aid of excellent exposure provided with the resection of $11^{\text {th }}$ rib (Department of Neurosurgery, Cumhuriyet University, with permission).

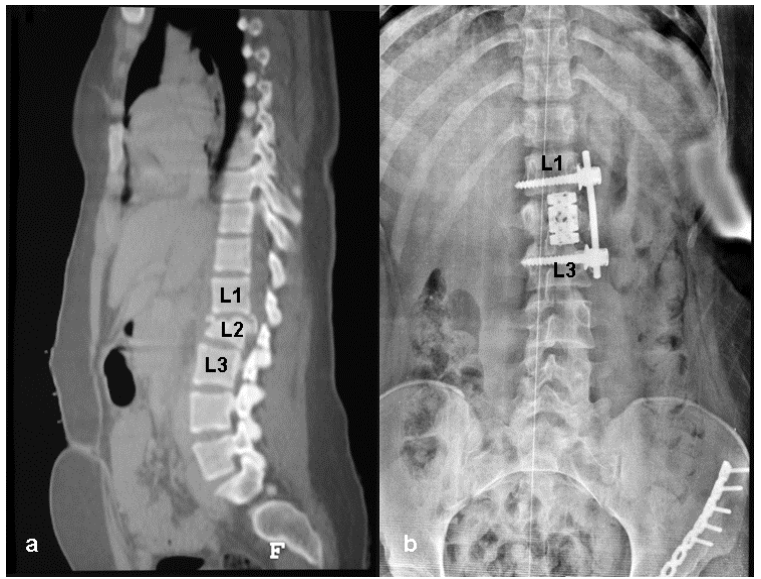

Fig. 10. Magnetic resonance imaging is showing traumatic vertebral fracture in L2 (a) and L2 corpectomy and stabilization was performed by the assistance with the resection of $12^{\text {th }}$ rib (b) (Department of Neurosurgery, Cumhuriyet University, with permission).

Apart from the patients requiring vertebral resection due to metastasis of lung cancer, anterior approach with thoracotomy is required in spine surgery for conditions such as trauma, tumor, hydatid cyst etc. A good preoperative assessment of the vertebrae to be intervened is important for good exposure during surgery. Our experience showed us, thoracotomy levels should be placed according to the level of T6-7. If the lesion placed above that limit, then thoracotomy should be performed at the lesion point. If the lesion placed below that level, then thoracotomy should be performed one or two vertebrae higher than the lesion point. 


\section{References}

[1] Mansour KA, DeLaRosa J. Anterior transthoracic approaches to the spine. In Shields TW, LoCicero J, Ponn RB, Rusch VW, ed. General Thoracic Surgery, vol 1, 6th ed. Philadelphia: Lippincott Williams and Wilkins; 2005:703-709.

[2] Nadir A, Sahin E, Ozum U, Karadag O, Tezeren G, Kaptanoglu M. Thoracotomy in spine surgery. Thorac Cardiovasc Surg 2008;56:482-84.

[3] Dwyer AF, Newton NC, Sherwood AA. An anterior approach to scoliosis. A preliminary report. Clin Orthop 1969;62:192.

[4] Levin R, Matusz D, Hasharoni A, Scharf C, Lonner B, Errico T. Mini-open thoracoscopically assisted thoracotomy versus video-assisted thoracoscopic surgery for anterior release in thoracic scoliosis and kyphosis: a comparison of operative and radiographic results. The Spine Journal 2005;5:632-8.

[5] Hitchon PW, Tomer J, Eichholz KM, Beeler SM. Comparison of anterolateral and posterior approaches in the management of thoracolumbar burst fractures. J Neurosurg Spine. 2006;5:117-25.

[6] Muschik MT, Kimmich H, Demmel T. Comparison of anterior and posterior double-rod instrumentation for thoracic idiopathic scoliosis:results of 141 patients. Eur Spine J 2006;1128-38.

[7] Schnee CL, Ansell LV. Selection criteria and outcome of operative approaches for thoracolumbar burst fractures with and without neurological deficit. J Neurosurg 1997;86:48-55.

[8] Denis F, Amstrong GW, Searls K, Matta L. Acute thoracolombar burst fractures in the absence of neurologic deficit: a comparison between operative and nonoperative treatment. Clin Orthop 1984;189:142-9.

[9] Liljengvist UR, Bullmann V, Schulte TL, Hackenverg L, Halm HF. Anterior dual rod instrumentation in idiopathic scoliosis. Eur Spine J 2006;15:1118-27.

[10] Jochen SH, Laurel B, Connie PK, George T. Video assisted thoracoscopic surgery in idiopathic scoliosis: evaluation of the learning curve. Spine 2007;32:703-7.

[11] Lapinsky AS, Richards BS. Preventing the crankshaft phenomenon by combining anterior fusion with posterior instrumentation. Does it work? Spine 1995;20:1392-8.

[12] Dai LY, Jiang SD, Wang XY, Jiang SY. A review of the management of thoracolumbar burst fractures. Surg Neurol 2007;67:221-31.

[13] Gurelik M, Goksel HM, Nadir A. Posterior mediastinal paravertebral hydatid cyst causing severe paraparesis. Br J Neurosurg. 2002; 16:605-6.

[14] Watkins R. Thoracic spine:anterior. In Herkowitz HN, Garfin SR, Eismont FJ, Bell GR, Balderston RA, ed. Rothman-Simeone Spine Surgery, vol 1, 5th ed, Philadelphia: Sunders Elsevier; 2006: 290-307.

[15] Thongtrangan I, Le HN, Park J, Kim DH. Thoracic and thoracolumar fractures. In Kim DH, Henn JS, Vaccaro AR, Dickman CA, ed Surgical anatomy\&Techniques to the spine $9^{\text {th }}$ ed, Philadelphia: Sunders Elsevier; 2006:352-363.

[16] Pettiford BL, Schuchert MJ, Jeyabalan G, Landreneau JR, Kilic A, Landreneau JP, Awais O, Kent MS, Ferson PF, Luketich JD, Peitzman AB, Landreneau RJ. Technical challenges and utility of anterior exposure for thoracic spine pathology. Ann Thorac Surg. 2008;86:1762-68. 
[17] Lu DC, Lau D, Lee JG, Chou D. The transpedicular approach compared with the anterior approach:an analysis of 80 thoracolumbar corpectomies: clinical article. J Neurosurg-Spine 2010;12(6);583-591.

[18] Janik JS, Burrington JD, Janik JE, Wayne ER, Chang JH, Rothenberg SS. Anterior exposure of spinal deformities and tumors: a 20 year experienceJ Pediatr Surg 1997;32:852-9.

[19] Naunheim KS, Barnett MG, Crandall DG, Vaca KJ, Burkus JK. Anterior exposure of the thoracic spine. Ann Thorac Surg 1994;57:1436-9. 


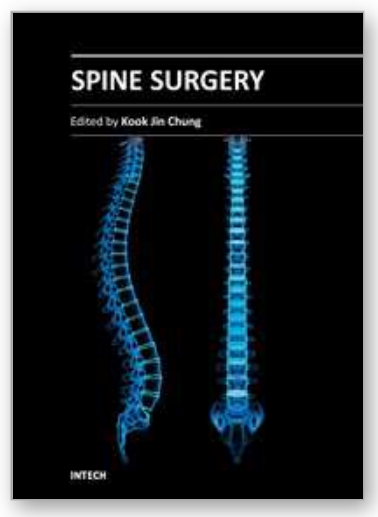

\author{
Spine Surgery \\ Edited by Dr. Kook Jin Chung
}

ISBN 978-953-51-0469-8

Hard cover, 148 pages

Publisher InTech

Published online 28, March, 2012

Published in print edition March, 2012

"Spine Surgery" is an authoritative and didactic textbook on the various fields of spine. It is written by many authors, internationally honorable experts to share their opinions with you. The chapters cover from anatomy of spine, spinal imaging technique, biology of spine, bone graft substitute, minimally invasive spinal surgery to even spinal deformity. It has many up to date results to help readers including university graduate students, medical instrumentation developers, and medical professionals including orthopaedic and neurosurgeons, rehabilitative professionals. The readers are provided with precious information and valuable guide in your daily practice.

\title{
How to reference
}

In order to correctly reference this scholarly work, feel free to copy and paste the following:

Aydın Nadir (2012). Anterior Approaches to Thoracic and Thoraco-Lumbar Spine, Spine Surgery, Dr. Kook Jin Chung (Ed.), ISBN: 978-953-51-0469-8, InTech, Available from: http://www.intechopen.com/books/spinesurgery/anterior-approaches-to-thoracic-and-thoraco-lumbar-spine-

\section{INTECH}

open science | open minds

\section{InTech Europe}

University Campus STeP Ri

Slavka Krautzeka 83/A

51000 Rijeka, Croatia

Phone: +385 (51) 770447

Fax: +385 (51) 686166

www.intechopen.com

\section{InTech China}

Unit 405, Office Block, Hotel Equatorial Shanghai

No.65, Yan An Road (West), Shanghai, 200040, China

中国上海市延安西路65号上海国际贵都大饭店办公楼 405 单元

Phone: +86-21-62489820

Fax: +86-21-62489821 
(C) 2012 The Author(s). Licensee IntechOpen. This is an open access article distributed under the terms of the Creative Commons Attribution 3.0 License, which permits unrestricted use, distribution, and reproduction in any medium, provided the original work is properly cited. 